Letters to the Editor

\title{
Fabrication of a Fiber-Optic-Based Electrochemiluminescence Sensor and Its Application to the Determination of Oxalate
}

\author{
Naoyoshi Egashira, Hirofumi Kumasako and Kazuya OHga \\ Department of Environmental Chemistry and Engineering, Faculty of Engineering, Oita University, \\ Oita 870-11, Japan
}

Keywords Electrochemiluminescence, optical fiber, sensor, oxalate, tris(2,2'-bipyridine)ruthenium(II)

Recent investigations have shown that the electrochemiluminescence (ECL) of tris(2,2'-bipyridine)ruthenium(II) $\left(\mathrm{Ru}(\mathrm{bpy}){ }_{3}{ }^{2+}\right)$ is useful for the determination of oxalate in electrolytic cells ${ }^{1}$ and of trialkylamines in flow-through cells. ${ }^{2}$ The determination of oxalate has also been carried out by use of a $\mathrm{Ru}(\mathrm{bpy}) 3^{2+}$ derivative fixed on $\mathrm{SnO}_{2}$ in the form of a Langmuir-Blodgett monolayer. $^{3}$ In these systems, light is produced according to the following reactions:

$$
\begin{aligned}
& \mathrm{Ru}(\mathrm{III})+\mathrm{C}_{2} \mathrm{O}_{4}{ }^{2-} \longrightarrow \mathrm{Ru}(\mathrm{II})+\mathrm{CO}_{2}+\mathrm{CO}_{2}-, \\
& \mathrm{Ru}(\mathrm{II})+\mathrm{CO}_{2}{ }^{-} \longrightarrow \mathrm{Ru}(\mathrm{I})+\mathrm{CO}_{2}, \\
& \mathrm{Ru}(\mathrm{I})+\mathrm{Ru}(\mathrm{III}) \longrightarrow \mathrm{Ru}(\mathrm{II})+\mathrm{Ru}(\mathrm{II})^{*}, \\
& \mathrm{Ru}(\mathrm{II})^{*} \longrightarrow \mathrm{Ru}(\mathrm{II})+h \nu .
\end{aligned}
$$

The first reaction is oxidation of oxalate by the anodically generated $\mathrm{Ru}$ (III) complex. The Ru(II) complex is easily reduced with the generated $\mathrm{CO}_{2}^{-}$to give the $R u(I)$ complex. Electron transfer from the $\mathrm{Ru}$ (I) to the $\mathrm{Ru}$ (III) gives an excited state of the $\mathrm{Ru}(\mathrm{II})$ which emits light.

The oxalate determination by the ECL is potentially suitable for biological samples containing many components, for example, urine and blood, since it can be conducted under milder conditions than that of chemiluminescence. ${ }^{4}$ However, the ECL systems reported hitherto are not small enough to be used for in vivo measurement of oxalate and have a possibility that $\mathrm{Ru}$ (bpy) ${ }_{3}{ }^{2+}$ is being continuously lost from the systems. We report here the fabrication and characterization of a miniaturized fiber-optic-based $\mathrm{Ru}(\mathrm{bpy})_{3}{ }^{2+} \mathrm{ECL}$ sensor for in vivo measurement. The design strategy is to place a working electrode against the end face of an optical fiber and to use $R u(b p y){ }_{3}{ }^{2+}$ immobilized into a Nafion film on the working electrode. Such a fiber optic sensor based on ECL, as far as we know, has not yet been reported.

\section{Experimental}

$\mathrm{Ru}(\mathrm{bpy})_{3} \mathrm{Cl}_{2}$ and Nafion 117 were purchased from
Aldrich Co. and used without further purification. A Nafion-modified electrode was prepared by dropping $3 \mu \mathrm{l}$ of $1 \mathrm{wt} \%$ Nafion solution (2-propanol $/ \mathrm{H}_{2} \mathrm{O}=9 / 1$ ) on a platinum plate electrode $\left(0.07 \mathrm{~cm}^{2}\right)$ and evaporating to dryness at room temperature. The modified electrode was dipped in $\left.1 \times 10^{-3} \mathrm{M} \mathrm{Ru(bpy)}\right)_{3}{ }^{2+}$ aqueous solution for $1 \mathrm{~h}$ to incorporate $\mathrm{Ru}(\mathrm{bpy})_{3}{ }^{2+}$ into the film and subsequently rinsed in deionized water for $1 \mathrm{~h}^{5}$

A plastic optical fiber (Mitsubishi Rayon, Esuka SH4001) of $1 \mathrm{~mm}$ in diameter mounted in a Teflon rod of $5 \mathrm{~mm}$ in diameter was surrounded by three electrodes. The configuration profile of the end of the fiber is represented in Fig. 1. The $\mathrm{Ru}(\mathrm{bpy})_{3}{ }^{2+} / \mathrm{Nafion}$-modified working electrode was placed against the end face of the fiber with a 2-mm space. The counter and reference electrodes were a $\mathrm{Pt}$ wire $(0.8 \mathrm{~mm}$ in diameter) and $\mathrm{Ag} / \mathrm{AgCl}$ electrode $(0.8 \mathrm{~mm}$ in diameter).

Figure 2 shows a diagram for the ECL sensor system. The potential was controlled with a Nikko Keisoku NPOT-2501 potentiostat. An electrolytic cell was enclosed in a lightproof box. The ECL was detected at room temperature with a Hamamatsu R928 photomultiplier operated at $900 \mathrm{~V}$ with a Hamamatsu C665
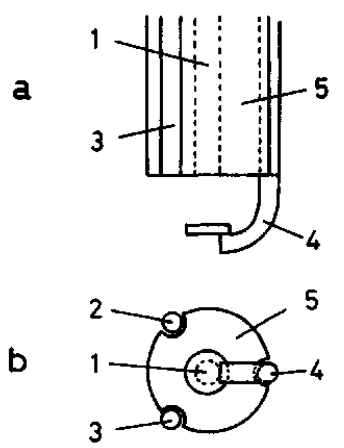

Fig. 1 Configuration profile of the end of the sensor: (a) sideview, (b) bottom-view; 1, plastic optical fiber; 2, Pt counter electrode; 3, Ag/ $\mathrm{AgCl}$ electrode; 4, working electrode; 5, Teflon rod. 


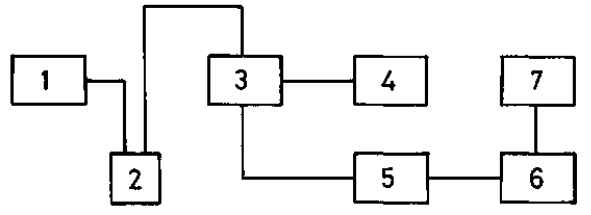

Fig. 2 Diagram for ECL measurement: 1, potentiostat; 2, ECL cell; 3, photomultiplier; 4, power supply; 5, galvanometer; 6 , filter; 7 , recorder.

high-voltage power supply. The output of the photomultiplier was amplified with a Yokogawa 2709 galvanometer which was coupled with a Kemo VBF/8 variable filter.

\section{Results and Discussion}

Figure 3 shows a typical signal for the ECL of $\mathrm{Ru}(\mathrm{bpy}){ }_{3}{ }^{2+}$ when the probe was immersed into $1 \times 10^{-3}$ $\mathrm{M}$ oxalate in $0.2 \mathrm{M}$ phosphate buffer of $\mathrm{pH} 6.8$ under stirring. When the potential was applied, the signal quickly increased and reached a stationary value in about $10 \mathrm{~s}$. The air-saturated solution was subjected to the ECL measurement since deaeration of the solution had little effect on the intensity of the ECL. Newly prepared probes were allowed to stand for $2 \mathrm{~h}$ in the buffer to obtain steady signals. The initial unstable response is probably attributable to the release of weakly bound $\mathrm{Ru}(\mathrm{bpy})_{3}{ }^{2+}$ from the film.

The intensity of the ECL depended on the applied potential and the film thickness. The ECL was detectable above $0.62 \mathrm{~V}$, and the intensity gave a maximum value at $0.80 \mathrm{~V}$ and steeply decreased above $0.80 \mathrm{~V}$. The intensity also increased with an increase in the film thickness and reached a maximum value at $2 \mu \mathrm{m}$. Thicker films showed lower intensity or occasionally no ECL. The decrease in the intensity may be due to a low $\mathrm{Ru}(\mathrm{bpy})_{3^{2+}}{ }^{2+}$ concentration at the Nafion-film/ electrode interface; the diffusion of $\mathrm{Ru}(\mathrm{bpy}) \mathrm{3}^{2+}$ in the film may be depressed by the accumulation of $\mathrm{Ru}(\mathrm{bpy})_{3}{ }^{2+}$. Thus, the optimal applied potential and film thickness were determined to be $0.80 \mathrm{~V}$ and $2 \mu \mathrm{m}$.

The intensity of ECL for $1 \times 10^{-3} \mathrm{M}$ oxalate was reproducible within $3 \%$ on 10 repeated runs. Even when the intensity decreased to about $80 \%$ of the initial stationary value after the use for 3 or $\mathbf{4 d}$, dipping of the probe into $\mathrm{Ru}(\mathrm{bpy})_{3}{ }^{2+}$ solution for $30 \mathrm{~min}$ allowed recovery to the initial value. This high stability strongly suggests that the probe will be of practical use in determining oxalate.

Figure 4 shows a linear calibration curve (correlation coefficient, 0.997 ) in the concentration range of $1 \times 10^{-4}$ to $1 \times 10^{-3} \mathrm{M}$. It should be noted here that a faint ECL was detected in the absence of oxalate. This ECL may be induced by the reaction of $R u(b p y) 3^{3+}$ generated on the electrode with hydroxide ion. ${ }^{6}$ The detection limit

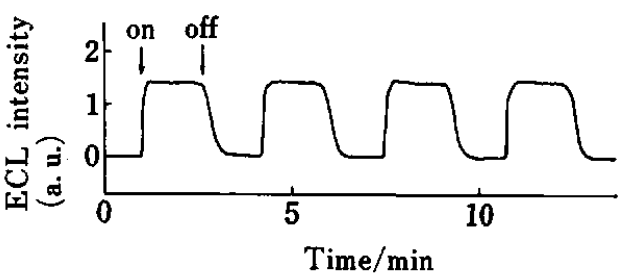

Fig. 3 Response of the sensor for $1 \times 10^{-3} \mathrm{M}$ oxalate in $0.2 \mathrm{M}$ phosphate buffer of $\mathrm{pH}$ 6.8. The applied potential and film thickness were $+0.80 \mathrm{~V}$ and $2 \mu \mathrm{m}$, respectively. On and off show whether the potential is applied or not.

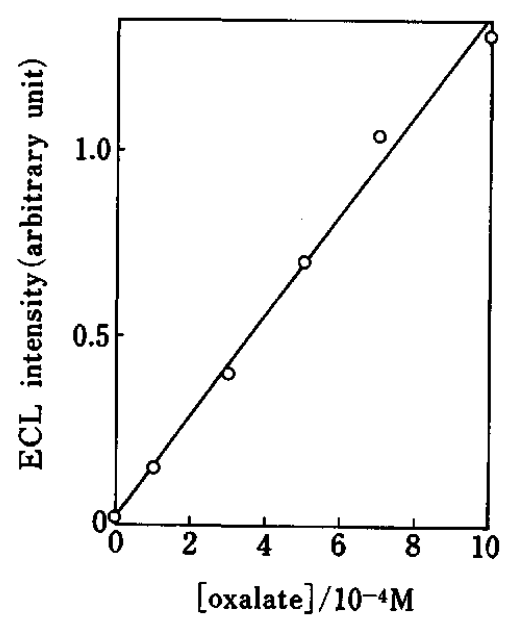

Fig. 4 A calibration curve for oxalate.

$(S / N=3)$ for oxalate was estimated to be $3 \times 10^{-5} \mathrm{M}$.

Normal urine $\left(5 \mathrm{~cm}^{3}\right)$ was mixed with $0.4 \mathrm{M}$ phosphate buffer $\left(5 \mathrm{~cm}^{3}\right)$. The oxalate concentration was determined to be $(4.9 \pm 0.5) \times 10^{-4} \mathrm{M}$ by the standard addition method; the other organic components in urine little showed ECL. The value lies in the oxalate concentration in normal urine. This result shows that the sensor can be used for biological samples.

\section{References}

1. I. R. Rubinstein, C. R. Martin and A. J. Bard, Anal. Chem., 55, 1580 (1983).

2. J. B. Noffsinger and N. D. Danielson, J. Chromatogr., 387, 520 (1987).

3. T. Sawaguchi, A. Ishio, T. Matsue, I. Uchida and K. Itaya, Denki Kagaku, 57, 1209 (1989).

4. D. F. Roswell and E. H. White, Methods Enzymol., 57, 409 (1978).

5. D. A. Buttry and F. C. Anson, J. Am. Chem. Soc., 104, 4824 (1982).

6. F. Lytle and D. M. Hercules, Photochem. Photobiol., 13, 123 (1971).

(Received June 8, 1990)

(Accepted September 12, 1990) 